\title{
Comparing Perception About Nursing Profession Among Degree, Diploma and Associate Nursing Students and Factors Influencing Enrolment in the Nursing Programs
}

\author{
Hisabu Kidane Gebremedhin ${ }^{1, \text { * }, \text { Zerabruk Tesfamariam Kidane }}{ }^{2}$, Eyasu Habte Tesfamariam ${ }^{3}$ \\ ${ }^{1}$ Department of Nursing, Orotta College of Medicine and Health Sciences, Asmara, Eritrea \\ ${ }^{2}$ Department of Community Medicine, Orotta College of Medicine and Health Sciences, Asmara, Eritrea \\ ${ }^{3}$ Department of Statistics, Eritrea Institute Technology, Mai Nefhi, Eritrea
}

Email address:

hsabugebre1982@gmail.com (H. K. Gebremedhin)

${ }^{*}$ Corresponding author

\section{To cite this article:}

Hisabu Kidane Gebremedhin, Zerabruk Tesfamariam Kidane, Eyasu Habte Tesfamariam. Comparing Perception About Nursing Profession Among Degree, Diploma and Associate Nursing Students and Factors Influencing Enrolment in the Nursing Programs. American Journal of Nursing Science. Vol. 9, No. 5, 2020, pp. 384-393. doi: 10.11648/j.ajns.20200905.22

Received: July 16, 2020; Accepted: August 12, 2020; Published: October 26, 2020

\begin{abstract}
Background: The variations between the perception of the profession of nursing and the reality of practice can lead to problems in student attrition or result in disappointment with a career in nursing after a new graduate enters practice. Objective: To assess and compare Nurses' Perception among Associate, Diploma and Degree nursing students about Nursing profession and factors influencing enrolment in the nursing programs in Eritrea. Methods: Institution based quantitative cross sectional study design was used. 403 intended study participants was selected from about 700 population using a multi stage systematic sampling method from the Bachelors of Science in Nursing, Diploma and Associate nursing students in the School of Nursing, Asmara College of Health Sciences and School of Associate Nurses (Mendefera, Barentu and Ghindae). Data collection was carried out using a pre structured questionnaire. The collected data was entered using CSPro version 6.3 and SPSS version 22.00 for further analysis. ANOVA and Odds ratio was calculated for perception difference and related factors. A p-value $<0.05$ was considered to be statistically significant. Results: The response rate was $92.06 \%, 371$ students. $228(61.5 \%)$ females and $143(38.5 \%)$ were males. $190(51.2 \%)$ associates, $128(34.5 \%)$ diploma and $53(14.3 \%)$ were degree nursing students. The tenet of public image and practice got significant difference among the three groups of nursing students, Values subscale revealed no significant differences. When controlling for demographic effect, practice and public image were significantly different among the groups. Associate nursing students' perception found significant difference in their view of the public image of nursing. In the seven out of the 14 factors influencing enrolment in the nursing programs significant association was found among the nursing students with their perception to the nursing profession. Conclusion: Associate nursing students have positive perception towards the profession and motivation to enroll than BSN and Diploma.
\end{abstract}

Keywords: Nurse's Perception, Profession, Influencing Factors, Nursing Students

\section{Introduction}

Nursing is not an easy profession to define, but effort has been made by many scholars and health organizations to define it. Among those definitions, Virginia Henderson defined Nursing practice as the unique function of the nurse, is to assist the individual, sick or well, in the performance of those activities contributing to health or its recovery (or to a peaceful death) that he/she would perform unaided if he/she had the necessary strength, will, or knowledge, and to do this in such a way as to help him/her to gain independence as rapidly as possible [1]. The other known definition of nursing is by the American Nurses Association (ANA), "Nursing is the protection, promotion, and optimization of health and abilities; prevention of illness and injury; alleviation of suffering through the diagnosis and treatment of human responses; and advocacy in health care for individuals, families, communities, and populations" [2]. On the other 
hand nurses' image and their values by Carol and Dawn are suggested in their book "Exploring Theories and Practice" that Nursing is a caring profession and the challenge for nurses is to personify the public's image of the caring professional nurse. As highlighted earlier, professionalism relates to a set of values, behaviors and relationships that are integral to the regulation of the profession and underpin the trust the public places in nurses [3]. The author's personal and professional experiences in Asmara College of Health Sciences or clinical sites have revealed that there are different viewpoints in which people or even nurse professionals as well as the students of nursing perceive nursing in different directions. Some assume nursing as if "it is a skill and doesn't have its code of ethics" others consider it as "it is only for females" and most assume nursing as if "it is only concerned with bed making and giving ordered drugs" and even others "think it is a helpful function to the physician without its own critical thinking that makes a profession." The query is how people really perceive nursing and particularly the actual perception among student nurses.

Researchers defined perception, as the way in which something is regarded, understood, or interpreted. Therefore, nursing as a concept is more than just a definition, it is part of a framework of communication, language of a group and this reflects who nurses are and the definition carries a person's perception. In addition to that, perception of nursing may vary depending on age, educational level, social and professional experience and occupational and social factors [4]. A study done in Ethiopia based on the reviewed literature of that study could assume that, perception is one's professional identity changes over the course of the 4 years of the nursing program [5]. A study of 1000 American nursing students' results revealed that students believed nursing to be physically challenging and that there is inadequate respect and recognition of nursing [6]. However a study by Sand-Jecklin and Schaffe reported that nursing students recognize nursing as a caring profession and as an opportunity to help people gain better health. The students most frequently reported choosing nursing because of the availability of career opportunities, jobs security, salary, and interest in nursing [7].

Although $70 \%$ of the public viewed the nursing carrier positively, there were some surprising differences between the public's opinions about the nursing profession versus opinions of registered nurses themselves. Eight percent of the public considered RNs as professionals, while only $23 \%$ of RNs considered themselves as professionals [8]. In addition to that study in Ghana, shown that there was a significant difference in the perception of nursing among the various years of training in the nursing school [9].

Another similar study in the US, revealed that ADN and BSN students were not different from each other but both student groups were significantly different from the RNs, who had more education than both student groups. Similarly, regarding the three tenets of the nursing perception (public image, practice and values) results revealed, average values for Practice and Public Image indicated that BSN students differed in their perceptions from the RNs to a greater extent than the ADN students [10].

A study conducted in Egypt, showed that the highest percent of studied subjects' perception of reasons to entering the nursing profession was helping others to cope with illness and followed by nurses who wanted to help people, while, around half of the sample disagreed saying that it was a childhood desire [11]. Lastly study in Ethiopia provided information about nurses perception towards nursing profession and factors affecting it, shown that there was knowledge gap in which nursing profession is predominantly recognized as female profession and limited to bedside care and drug administration instead of highly skilled and well educated nursing professional with important role to play in health care [12]. The main purpose of this study is to assess and compare the perception of BSN, Diploma and Associate nurse students about the nursing profession and factors influencing enrolment in the nursing programs.

\section{Research Hypothesis}

$\mathrm{H}_{\mathrm{ol}}=$ There is no significant difference among the three categories of nursing students in their perception to the nursing profession.

$\mathrm{H}_{\mathrm{Al}}=$ There is significant difference among the three categories of nursing students in their perception to the nursing profession

$\mathrm{H}_{\mathrm{o} 2}=$ There is no significant association between perception to the nursing profession and factors influencing enrolment in the nursing programs among the three categories of nursing students.

$\mathrm{H}_{\mathrm{A} 2}=$ There is a significant association between perception to the nursing profession and factors influencing enrolment in the nursing programs among the three categories of nursing students.

\section{Methods}

\subsection{Study Area and Period}

The study was conducted in Eritrea, Asmara College of Health Sciences (ACHS), and Schools of Associate Nurses that are run under the $\mathrm{MOH}$ Eritrea. The ACHS, located in Asmara the capital city of Eritrea and the Schools of Associate Nurses are in three different administrative regions of Eritrea which are Ghindae in Northern Red Sea, Mendefera in South and Barentu in Gash Barka.

The study was conducted from October 2017 to June 2018 (9months duration).

\subsection{Study Design}

Institution based quantitative cross sectional study design was used.

\subsection{Source of Population}

Nursing students who are registered in the School of Nursing in the ACHS in Degree and Diploma in 2017/2018 
and Associate Nursing students enrolled in the three schools of Associate Nursing in the same period.

\subsection{Sample Size and Sampling Procedure}

\subsubsection{Sample Size}

The sample size was determined by using a formula for estimating a single population proportion. Since there is no study done on this topic, the sample size for this cross sectional study was calculated by assuming prevalence to be $50 \%$.

The sample size of the study was based on having $95 \%$ confidence interval and tolerable margin of error is $5 \%$ plus the $5 \%$ non-response rate.

$$
n=(\mathrm{Z} \alpha \cdot 2)^{2} P(q) \div d^{2}
$$

Where: $n=$ sample size

$\mathrm{Z}=95 \%$ confidence interval which is 1.96

$\alpha / 2=$ significance level which is less or equal to 0.05

$\mathrm{p}=$ probability of population which is 0.5

$\mathrm{q}=1-\mathrm{p}$ (1minus the probability)

$\mathrm{d}^{2}=$ degree of precision

$\mathrm{n}=(1.96)^{2} \times 0.5(1-0.5) /(0.05)^{2}=384$ was the total sample size.

Adding 5\% non-response rate, the total sample size required for this study turns out to be 403 students.

\subsubsection{Sampling Procedure}

The total population in all the study sites were around 700 students. So from this proportionate a multi stage systematic random sampling technique was used to select intended study subjects from all three schools of associate nurses and from the diploma sections and years of study and same from the BSN years of studies. List of nursing students was taken from each school then the selection of 403 nursing students was performed using the following formula from the sample frame.

$$
n j=\frac{n \times N j}{N}
$$

Where $\mathrm{nj}$ - sample size in $\mathrm{j}$ program

$\mathrm{n}$ - Estimated final sample size

$\mathrm{Nj}$ - Total number of nursing students in $\mathrm{j}$ program

$\mathrm{N}$ - Total nursing students in the schools

Proportional allocations of the study subjects to the schools of nursing students will be as follows:

I. School of Associate Nurses

$$
\begin{gathered}
370 / 707 \times 403=211 \\
n j 1=\frac{n \times N j 1}{N}
\end{gathered}
$$

Wherenj 1 -sample size in $\mathrm{j} 1$ School

$\mathrm{Nj} 1$ - Total number of nursing students in $\mathrm{j} 1$ school

Barentu School of associate nurse $\frac{129}{707} \times 403=74 K^{\text {th }}=$ $129 / 74=1.7 \approx 2$

Mendefera School of associate nurse $\frac{136}{707 x} 403=77 K^{\text {th }}=$
$136 / 77=1.8 \approx 2$

Ghindae School of associate nurse $\frac{105}{707 x} 403=60 K^{\text {th }}=$ $105 / 60=1.8 \approx 2$

II. Asmara College of Health Sciences (ACHS)

a. BSN program $93 / 707 x 403=53$

$$
\begin{gathered}
\left(4^{\text {th }} \text { year } 40 / 707 \times 403\right)=23 K^{\text {th }}=40 / 23=1.7 \approx 2 \\
\left(3^{\text {rd }} \text { year } 27 / 707 x 403\right)=15 K^{\text {th }}=27 / 15=1.8 \approx 2 \\
\left(2^{\text {nd }} \text { year } 26 / 707 \times 403\right)=15 K \text { th }=26 / 15=1.7 \approx 2
\end{gathered}
$$

b. Diploma program $244 / 707 x 403=139$

$$
\begin{aligned}
& \left(3^{\text {rd }} \text { year } 72 / 707 \times 403\right)=41 K^{\text {th }}=72 / 41=1.8 \approx 2 \\
& \left(2^{\text {nd }} \text { year } 76 / 707 \times 403\right)=43 K^{\text {th }}=76 / 43=1.8 \approx 2 \\
& \left(1^{\text {st }} \text { year } 96 / 707 \times 403\right)=55 K^{\text {th }}=96 / 55=1.7 \approx 2
\end{aligned}
$$

\subsection{Inclusion and Exclusion Criteria}

Nursing students who registered in the academic year $2017 / 018$, willing to participate and those students who were new to the profession were included in the study. Whereas experienced nursing students, unwilling to participate and those were absent at time of data collection were excluded from the study.

\subsection{Data Collection Tools}

The data collection was carried out using a selfadministered structured questionnaire which was adopted from the study conducted in US [7] and that was cited in [10] to measure the perceptions of nursing among nursing students with some modification in the biographic data. The questionnaire contains 9 socio - demographic characteristic; Age, sex, ethnic group, marital status, admission year, religion, place of residence. Thirty seven Professional Perception Nursing Tool (PPNT) stem questions used to assess nurses' perception towards nursing profession which was designed as a 5-pointlikert scale which ranges from strongly disagree to strongly agree. The last part was an assessment tool checklist adopted from a study in India [15] for evaluating the factors influencing enrolment to Nursing Colleges, which contains 14 items.

\subsection{Data Analysis}

Data was cleared using Census and Survey Processing System (CSPro) version 6.3 for completeness and analyzed using SPSS version 22. Each of the perception factor subscale scores was compared by the categories of the demographic characteristics using the One-Way Analysis of Variance (ANOVA) procedure with Scheffe Post-Hoc test (as appropriate) and after controlled the demographic effect factorial analysis was used to find association among the study profession and the PPNT subscales. In addition to this, the binary regression was used to assess any association between the perceptions of the nursing students to the profession and the factors influencing enrolment in nursing 
programs. Finally, the results were presented using tables and assessed for any associations or differences using $\alpha=0.05$ with a confidence interval of $95 \%, \alpha \leq 0.05$ was considered a significant association or difference.

\section{Results}

\subsection{Demographic Characteristics}

Table 1 below presents the demographic characteristics of the study participants. Half of the study participants $(n=190$, $51.2 \%)$ from the sample $(\mathrm{N}=371)$ were associate nurse students, followed by diploma nursing students $(\mathrm{n}=128$, $34.5 \%)$ and $53(14.3 \%)$ were BSN students.

Table 1. Demographic characteristics of the study professions.

\begin{tabular}{llll}
\hline Characteristics & & Number & Percent \\
\hline study profession & & & \\
& Associate nurse & 190 & 51.2 \\
& Diploma nurse & 128 & 34.5 \\
& Degree Nurse & 53 & 14.3 \\
Admission Year & & & \\
& Before 2016 & 63 & 17.0 \\
& $2016 / 2017$ & 71 & 19.1 \\
Age in Years & $2017 / 2018$ & 237 & 63.9 \\
& & & \\
& $18-19$ & 176 & 47.4 \\
& $20-21$ & 171 & 46.1 \\
Gender & 22 and above & 24 & 6.5 \\
& & & \\
& Male & 143 & 38.5 \\
Religion & Female & 228 & 61.5 \\
& & 299 & 80.6 \\
& Christian & 65 & 17.5 \\
& Moslem & 7 & 1.9 \\
\hline
\end{tabular}

\begin{tabular}{llll}
\hline Characteristics & & Number & Percent \\
\hline Place of Residence & & & \\
& Urban & 276 & 74.4 \\
& Rural & 95 & 25.6 \\
Ethnicity & & & \\
& Tigrigna & 303 & 81.7 \\
& Tigre & 38 & 10.2 \\
& Others & 30 & 8.1 \\
\hline
\end{tabular}

\subsection{Comparison of the Overall Perception of the Study Participants}

Positive perception towards their profession of Associate, Diploma and BSc nursing students were significantly different $(p<0.001)$ (Table 2). Post-hoc Scheffe (Table 3) results of the differences in perception revealed that nurses at degree level had significantly lower positive perception than associate nurses $(<0.001)$ and diploma nurses $(\mathrm{p}=0.005)$. On the other hand, diploma nurses had higher positive perception than degree nurses $(p=0.002)$. Moreover, an increasing positive perception was observed with decrease in professional level $(\mathrm{p}<0.001)$. Positive perception was also found to be significantly different among nurses admitted in the three different years $(\mathrm{p}<0.001)$. Upon investigating the difference in positive perception using post-hoc Scheffe, (Table 3) nurses admitted in 2017/18 had higher positive perception than nurses admitted before $2016(p<0.001)$. However, no significant difference in positive perception was observed among nurses who were admitted in 2016/17 in comparison to both nurses admitted before $2016(\mathrm{p}=0.239)$, as well as in $2017 / 18(p=0.056)$. On the other hand, a significant trend of positive perception was observed as the time for admission of the nurses becomes later $(p<0.001)$.

Table 2. Comparison of the overall perception of the study participants across categories of demographic characteristics.

\begin{tabular}{|c|c|c|c|c|c|}
\hline Source & & M (SD) & $F(d f)$ & p-Value & p- trend \\
\hline \multicolumn{3}{|c|}{ Profession of nursing students } & $1.74(2)$ & $<0.001$ & $<0.001$ \\
\hline & Associate Nurse & $140.64(12.50)$ & & & \\
\hline & Diploma nurse & $136.17(10.83)$ & & & \\
\hline & Degree Nurse & $129.48(12.40)$ & & & \\
\hline \multirow[t]{4}{*}{ Admission Year } & & & $0.05(2)$ & $<0.001$ & $<0.001$ \\
\hline & Before 2016 & $132.02(11.94)$ & & & \\
\hline & 2016/2017 & $135.56(12.39)$ & & & \\
\hline & $2017 / 2018$ & $137.48(12.40)$ & & & \\
\hline \multirow[t]{4}{*}{ Age } & & & $1.01(2)$ & 0.779 & 0.48 \\
\hline & $18-19$ & $137.92(11.95)$ & & & \\
\hline & $20-21$ & $137.18(12.96)$ & & & \\
\hline & above 22 & $136.42(12.40)$ & & & \\
\hline \multirow[t]{4}{*}{ Ethnicity } & & & $0.44(2)$ & 0.391 & 0.269 \\
\hline & Tigrigna & $137.08(12.46)$ & & & \\
\hline & Tigre & $139.76(11.59)$ & & & \\
\hline & Others & $138.67(1287)$ & & & \\
\hline
\end{tabular}

Table 3. Post Hock test for study profession and admission year.

\begin{tabular}{lllll}
\hline Variables & & Mean Difference MD & Std. Error & p-value \\
\hline study profession & & & & \\
Associate nurse & Diploma Nursing & 4.47 & 1.35 & 0.005 \\
& BSN & 11.32 & 1.83 & $<0.00$ \\
Diploma Nursing & BSN & 6.85 & 1.91 & 0.002 \\
Admission year & & & & \\
Before 2016 & $2016 / 2017$ & -3.55 & 2.09 & 0.239 \\
\hline
\end{tabular}




\begin{tabular}{|c|c|c|c|c|}
\hline Variables & & Mean Difference MD & Std. Error & p-value \\
\hline & $2017 / 2018$ & -7.49 & 1.71 & $<0.001$ \\
\hline $2016 / 2017$ & $2017 / 2018$ & -3.94 & 1.64 & 0.056 \\
\hline
\end{tabular}

According to table 4, nurses who were residing in rural areas $(M=139.9, S D=12.72)$ were having higher positive perception towards their profession as compared to those residing at urban areas $(\mathrm{M}=136.64, \mathrm{SD}=12.21),(\mathrm{p}=0.027)$. However, no difference in perception was observed across the categories of gender $(p=0.609)$ and religion $(p=0.371)$.

Table 4. Independent t- Test for the categorical variables, gender, religion and place of residence.

\begin{tabular}{lllll}
\hline Variable & & M (SD) & $\mathbf{( 9 5 \% C I ) ~}$ & p-value \\
\hline Gender & & & $-3.28,1.93$ & 0.609 \\
& Male & $137.06(12.61)$ & & \\
\multirow{4}{*}{ Religion } & Female & $137.74(12.29)$ & & \\
& & & $4.79,1.79$ & 0.371 \\
& $\begin{array}{l}\text { Christian } \\
\text { Place of residence } \\
\text { Moslem }\end{array}$ & $137.21(12.29)$ & & \\
& Urban & $138.71(11.99)$ & & \\
& & $3.26,1.47$ & 0.027 \\
& Rural & $139.64(12.21)$ & & \\
\hline
\end{tabular}

In order to control the confounding effect, variables that were significant at one way ANOVA and independent samples t-test were further analyzed using factorial ANOVA (Table 5). Upon controlling the confounding effects, both study profession $(\mathrm{p}<0.001)$ and admission year $(\mathrm{p}=0.0407)$ were found to significantly affect the perception of the nurses but not the place of residence $(\mathrm{p}=0.097)$. Moreover, the study profession (partial eta squared $=0.056$ ) was found to be higher in contribution in determining the variance in perception of the nurses than admission year (partial eta squared $=0.017$ ).

Table 5. Factorial ANOVA of the total perception score by study profession, admission year and place of residence.

\begin{tabular}{llll}
\hline Variables & p-value & Partial Eta Squared & Observed Power $^{\mathbf{b}}$ \\
\hline Study Profession & $<0.001$ & 0.056 & 0.990 \\
Admission year & 0.0407 & 0.017 & 0.614 \\
Place of Residence & 0.097 & 0.008 & 0.382 \\
\hline
\end{tabular}

b. computed using alpha $=.05$

Positive perception was shown in the public image subscale towards their profession among Associate, Diploma and Degree nursing students with significant difference $(p<0.001)$ (Table 6). Post-hoc Scheffe (Table 7) results of the differences in public image subscale perception revealed that nurses at degree level had significantly lower positive perception than Associate nurses $(p=0.001)$ and Diploma nurses $(p=0.008)$. On the other hand, diploma nurses had higher positive perception than degree nurses $(p<0.001)$. Moreover, an increasing positive public image perception was observed with decrease in professional level $(\mathrm{p}<0.001)$. In addition to that, positive nursing practice subscale perception was also found to be significantly different among student nurses $(p<0.013)$. Upon investigating the difference in positive perception in practice subscale, using post-hoc
Scheffe (table 7), Diploma nursing students had higher positive perception of the practice subscale than the BSN students $(p=0.024)$. However, no significant difference in positive perception practice subscale was observed among the other study groups. On the other hand no significant difference $(\mathrm{p}=0.478)$ observed among the study participants towards the nursing values perception subscale.

Table 6. Comparison of perceptions on public image, values and practice across study professions.

\begin{tabular}{|c|c|c|c|c|}
\hline Variable & M (SD) & F (df) & p-Value & p- trend \\
\hline \multicolumn{5}{|l|}{ Public Image } \\
\hline Study Profession & & $44.38(2)$ & $<0.001$ & $<0.001$ \\
\hline Associate Nurse & \multicolumn{4}{|c|}{$46.84(7.66)$} \\
\hline Diploma nurse & \multicolumn{4}{|c|}{$43.96(7.75)$} \\
\hline Degree Nurse & \multicolumn{4}{|c|}{$35.15(9.58)$} \\
\hline \multicolumn{5}{|l|}{ Values } \\
\hline Study Profession & & $0.739(2)$ & 0.478 & 0.241 \\
\hline Associate Nurse & \multicolumn{4}{|c|}{$41.66(3.92)$} \\
\hline Diploma nurse & \multicolumn{4}{|c|}{$41.23(3.86)$} \\
\hline Degree Nurse & \multicolumn{4}{|c|}{$41.43(3.84)$} \\
\hline \multicolumn{5}{|l|}{ Practice } \\
\hline Study Profession & & $4.37(2)$ & 0.013 & 0.826 \\
\hline Associate Nurse & \multicolumn{4}{|c|}{$52.14(4.71)$} \\
\hline Diploma nurse & \multicolumn{4}{|c|}{$50.09(4.75)$} \\
\hline Degree Nurse & \multicolumn{4}{|c|}{$53.09(4.61)$} \\
\hline
\end{tabular}

Table 7. Post Hoc Multiple Comparisons for the public image and practice subscale among the Associate, Diploma and BSN nursing students.

\begin{tabular}{llll}
\hline Variables & Sample & Mean difference & p- value \\
\hline $\begin{array}{l}\text { Public image } \\
\text { Study profession }\end{array}$ & & & \\
Associate & Diploma & 2.88 & 0.008 \\
& BSN & 11.69 &, 0.001 \\
Diploma & BSN & 8.81 & $<0.001$ \\
Practice & & & \\
Study profession & & & \\
Associate & Diploma & 1.16 & 0.101 \\
& BSN & -0.95 & 0.43 \\
Diploma & BSN & -2.11 & 0.024 \\
\hline
\end{tabular}

\subsection{Association of Nursing Perception and Factors Influencing Enrolment in the Nursing Programs}

Table 8 displays results of association between the study participants' perception and the external influencing factors that led them to enroll in the nursing programs. According to the results, most of the factors shown no association among the different categories of nursing professions. However, in the factors the study participants enrolled in the nursing program the results revealed that, Associate nursing students were $2.8(\mathrm{p}=0.013)$ times more influenced by the previous presence of relatives/friends in nursing than the BSN but no association seen between the BSN and diploma $(p=0.101)$ nursing students. Similarly, the reasons for enrolment in nursing programs as influenced by the opportunities of the 
government good salary and attraction of nursing socioeconomic benefit were $3.4(p=0.002)$ and $3(p=0.003)$ times respectively, more in associate nursing students than for the BSN, but no association with diploma nursing students $(p=0.053$ and 0,051$)$ respectively. Over all, there was no association in the other factors.

Table 8. Association of nursing perception and external factors influencing enrolment in the nursing programs.

\begin{tabular}{lcc}
\hline External Factors & COR (95\% CI) & p-value \\
\hline Service to mankind as God's service (Ref. BSN students) & 0.252 \\
Associate nurse & $0.56(0.26-1.19)$ & 0.128 \\
Diploma Nurse & $0.73(0.33-1.62)$ & 0.435 \\
Nursing gives 100\% job guarantee (Ref. BSN students) & 0.374 \\
Associate nurse & $0.78(0.42-1.43)$ & 0.423 \\
Diploma Nurse & $0.64(0.34-1.22)$ & 0.171 \\
Availability of job everywhere (Ref. BSN students) & 0.544 \\
Associate nurse & $0.71(0.38-1.32)$ & 0.277 \\
Diploma Nurse & $0.79(0.41-1.53)$ & 0.487 \\
Religious influence (Ref. BSN students) & & 0.151 \\
Associate nurse & $0.49(0.24-1.01)$ & 0.052 \\
Diploma Nurse & $0.62(0.29-1.29)$ & 0.198 \\
Relative/friends already in Nursing (Ref. BSN students) & 0.036 \\
Associate nurse & $2.79(1.24-6.28)$ & 0.013 \\
Diploma Nurse & $2.04(0.87-4.75)$ & 0.101 \\
Parental/peer encouragement (Ref. BSN students) & 0.223 \\
Associate nurse & $1.72(0.93-3.18)$ & 0.084 \\
Diploma Nurse & $1.57(0.83-3.00)$ & 0.168 \\
Opportunities government good salary (Ref. BSN students) & 0.004 \\
Associate nurse & $3.41(1.57-7.38)$ & 0.002 \\
Diploma Nurse & $2.22(0.99-4.99)$ & 0.053 \\
Attracted to socioeconomic benefit of nursing (Ref. BSN students) & 0.01 \\
Associate nurse & $3.06(1.45-6.45)$ & 0.003 \\
Diploma Nurse & $2.18(0.99-4.74)$ & 0.051 \\
\hline
\end{tabular}

According to Table 9, most of the factors influencing enrollment in the nursing programs shown association. Generally in the influencing factors self-motivated to enroll in the program, Associate nursing students were 3.4 times more self-motivated than the BSN $(p=0.002)$ but not with the diploma $(\mathrm{p}=0.566)$.

Associate nurses who were enrolled $3.79(\mathrm{p}=0.001)$ times more influenced by personal liking and willing to work hard than the degree nurses.

In addition to that, the associate as well as the diploma nursing students were $5.65(\mathrm{p}<0.001)$ and $2.8 \quad(\mathrm{p}=0.005)$ times, respectively, more influenced enrollment in the nursing programs than the BSN students due to the factor of 'pre-educational experience'. Conversely, the BSN students were enrolled in the nursing programs as they couldn't get other options than nursing, as compared to the Associate nursing students, $2.38 \quad(\mathrm{p}=0.019)$, but there was no association showed between the BSN and diploma.

However, in the two internal factors which are desired to help those in need and for further personal and professional development, there was no significant association among the three categories of nursing students with $(\mathrm{P}=0.721$ and0.193), respectively.
Table 9. Association of nursing perception and internal factors influencing enrolment in the nursing programs.

\begin{tabular}{lcl}
\hline Internal Factors & COR (95\% CI) & p-value \\
\hline Desire to help those in need (Ref. BSN students) & 0.721 \\
Associate nurse & $0.89(0.32-2.48)$ & 0.817 \\
Diploma Nurse & $1.23(0.39-3.79)$ & 0.719 \\
Self-motivated (Ref. BSN students) & & 0.001 \\
Associate nurse & $3.36(1.58-7.15)$ & 0.002 \\
Diploma Nurse & $1.24(0.6-2.5)$ & 0.566 \\
Personal liking and willing to work hard (Ref. BSN students) & 0.005 \\
Associate nurse & $3.79(1.67-8.59)$ & 0.001 \\
Diploma Nurse & $1.86(0.84-4.12)$ & 0.124 \\
Pre educational experience (Ref. BSN students) & $<0.001$ \\
Associate nurse & $5.65(2.82-11.29)$ & $<0.001$ \\
Diploma Nurse & $2.8(1.37-5.73)$ & 0.005 \\
For farther development (Ref. BSN students) & 0.193 \\
Associate nurse & $2.02(0.94-4.38)$ & 0.074 \\
Diploma Nurse & $1.79(0.79-4.04)$ & 0.161 \\
There was no other option/choice than nursing (Ref. BSN students) & $<0.001$ \\
Associate nurse & $2.38(1.15-4.92)$ & 0.019 \\
Diploma Nurse & $0.71(0.31-1.60)$ & 0.405 \\
\hline
\end{tabular}

\section{Discussion}

\subsection{Analysis of Nursing Perception}

Two studies in the literature that contrasted nursing students in different levels of education included a research that compared different levels of nursing professionals of their Nurses' perceptions associated with perception towards their profession and factors affecting it in Debre Berhan Ethiopia [12] and study [13]that dealt with psychosocial factors influencing the perception and choice of nursing as a profession and which examined the perception of nursing students in choosing nursing among different levels of nursing students in Ghana. Those studies [12, 13] found significant differences for the perception subscales among educational levels of nursing students. In the current study Associate nursing students had higher scores in relation to esthetic, public image, and practice perception subscales than Diploma and BSN student nurses. Nonetheless in case of the current study the expectation was for the BSN students to be higher in perception, however the results showed that, the Associate nursing students had higher than the Diploma and BSN students. This finding may be because most of the BSN students were enrolled in the nursing programs as a result of limited option to join medicine. Conversely, neither [12] nor [13], compared student groups to perception practice subscale.

Similar to the current study, a study in the US [10] found that senior nursing students in Associate Degree Nurse (AND) and BSN programs did not differ significantly on the total subscale of values, and a significant difference was found on the total practice subscale also. But unlike the study done in the US [10], significant difference was found in public image subscale in the current study.

A recent study [11], examined the nursing profession as perceived by staff nurses and its relation to their career commitment at different hospitals. Similar to the findings of the current study, they found that there was a statistically 
significant difference between the perception of nurses toward the profession and the different levels of nursing students, year of admission and place of residence. Likewise, there was no significant difference in the cases of age, religion, gender and ethnicity, in a similar manner to the current study. In the study [11] unlike the current one, the researchers did not classify the perception scale in to sub scales.

Another similar study that was done in Iran cited in [16] first and fourth-year student's perceptions about importance of nursing care behaviors compared using Mann-Whitney U tests, there was significant difference only among one of the six studied dimensions. Fourth-year students ranked the dimension "explains and facilitates" higher than the firstyear students. The relationship between demographic characteristics of nursing students, with importance of caring dimensions was determined. There were no statistically significant differences between students' perceptions of caring dimensions, except for the relationship between sex of the first-year student and the whole of caring dimensional which have been found statistically significant differences. In that case, female students evaluated caring dimensions with higher scores than their counterpart the male students. However, unlike the above study, no significant difference occurred in the current study among the three categories of nursing students in case of gender, age, religion and ethnicity.

A study done in Cairo Egypt [17], revealed that correlation coefficient for age and level of education in relation to the total score of perception showed a positive correlation between the level of education and the perception, while there was no correlation between age and perception. This is similar to the current study in terms of age, as results revealed no significant difference between the three categories of nursing students in their age group, but in case of comparing levels of nursing students' perception about the profession showed a significant difference like the study stated above.

\subsection{Assessment of Association Between Perception About Nursing Profession and Factors Influencing Enrollment in the Nursing Programs}

This part tries to assess any association among the three categories of nursing students' total score of perception to the factors influencing enrolment into the nursing programs. For the purpose of analysis, the total 14 questionnaires, which were developed by Momin [19] have been classified into two subgroups which are internal (6 questions) and external factors (8). The results of the current study showed that three items 'Relative/friends already in Nursing, Opportunities of government good salary, and Attracted by the socioeconomic benefits of nursing' from the external factors and four items (Self-motivated, Personal liking and willing to work hard, Pre-educational experience, and there was no other option/choice than nursing) from the internal influencing factors had significant association among the three categories of nursing students. This may be because the BSN and diploma nursing students had no enthusiasm to enroll in nursing, but joined because of the limitation of choice. Especially the BSN students according to their additional report, they chose nursing as a profession, as it is nearer to medicine. Those reasons may have contributed great to them to perceive nursing negatively than the Associate nursing students. A study [7] in a similar manner to the current study stated that, students most frequently reported choosing a career in nursing because of "wanting to help others/make a difference", followed by "having had positive personal experiences/role models in nursing". Additionally, in the study [7], the availability of a variety of career opportunities was identified by 12 percent of students. Other reasons for choosing nursing, including job security/salary, interest in nursing, and challenging/rewarding career, were also identified by 5 percent of respondents or fewer. Students most frequently identified "pursuing further education" as a career goal, followed by "doing one's best in nursing/making a difference and specializing in a nursing field". Where as in the current study in the influencing factors to enroll to the profession, 'relatives/friends already in Nursing, Opportunities of government good salary, attracted to socioeconomic of benefit of nursing, self-motivated, personal liking and willing to work hard, pre-educational experience, and there was no other option/choice than nursing' had a significant association between the influencing factors and perception of nursing profession.

There was a positive correlation between most nurses' reasons for entering the profession and their perception of career commitment [11]. There was no relation between nurses needing to help people, earning good salary and friends' advice as reasons for entering the nursing profession and career commitment, but a positive correlation demonstrated between nurses' perception regarding their profession and their career commitment. In the same way, results of a study [17] about nursing students' perception regarding nursing programs in Cairo, Egypt, support the current study in that age and the perception of associate nurse had no significant difference.

A study in the US [18], stated that students who identified "Desire to help others" as a reason for choosing the nursing profession had significantly more positive perceptions of the items in the "Decision making regarding nursing" sub-scale than students who did not identify this as a reason for choosing nursing. This differed from the current study as it found no significant association between choosing nursing and the students 'perception of nursing.

In the study [18], students who identified "Diversity of job opportunities", "Religious influence" and "Exposure to family and friends in the healthcare profession" as a reason for choosing the nursing profession had more positive perceptions of the items in the "Decision making regarding nursing" sub-scale than those who did not identify this as a reason for choosing nursing. In contrast, in the current study "Availability of job everywhere", "Religious influence" and "Parental/peer encouragement" had a negative influence to choose nursing and had no any significant association with 
the nursing students' perception of the profession. The results of the comparisons [18], showed that one of the subscale scores, "Decision making regarding nursing" was found to be significantly different by categories of the variable of investigation. Students who indicated "Prior work experience", "Salary opportunities" and "Hands on caring for family and friends" this was accomplished by using the independent t-test and no significant differences were found in the three subscale scores as a reason for choosing the nursing profession. But regarding the similar questions in the current research, there was a significant association among the three categories of nursing students concerning the influencing factors and their perception to the nursing profession.

A similar study [20], on the comparison between nurses' professional needs and their perceptions of their job showed that the difference between nurses' overall role conception and their perception of the actual roles was significant. Overall, nurses rated their work values significantly higher than their perceptions of the environmental attributes. On the other hand the researcher found that, there were large discrepancies between nurses' need and the actual rewards they received in terms of opportunity for higher income and reward with recognition. Slightly different results were observed in the 'organizational support' factor represented by the last four items (clear rules to follow, regular routine, respectable superior and job security) in the study [20]. There was a smaller discrepancy between nurses' needs and the actual support they received from their hospitals, compared with the difference in the professional rewards factor. However, this moderate discrepancy originated from nurses not wanting organizational rules and routines to follow. In particular, nurses' need for rules to follow was low, and this is the only factor where actual opportunity exceeded nurses' needs. That study is similar to the current study which showed that there was a significant association in the internal factors influencing enrollment to the nursing programs (table 8 ). However only in three items out of the eight in the external factors (table 9) was significant association found among the three categories of nursing students.

In another area, results of another similar study to the current research [13], indicated that the relationship between parental influence and choice of the nursing profession among the students at Korle-Bu nurses training college in Ghana was significant. That study differed with current study, as the findings of this research had no significant association between parental influence and nursing perception among the study groups.

A study done in Egypt [17] on nursing students' perception regarding nursing programs, results showed that comparison between the different reasons to join nursing and mean total score of perception, revealed the highest mean total score was between the self-motivated students as a reason to join nursing. That study supported the current study as the results showed significant association between the perception of nursing profession and factors enrollment the nursing programs among the study participants.

\section{Conclusion}

This study is aimed at finding the perception of student nurses about the nursing profession and factors influencing enrolment into the nursing programs. Additionally tries to seek the association of influential factors for enrolment and the nurse students' perception about the nursing profession.

This study found that the perception of public image and practice differed significantly among the three categories of nursing students.

In view of this, two hypotheses were stated. The first finding was, in the general nursing perception, which had a significant difference among the Associate nurse, Diploma nurse and BSN students. However, unexpectedly the Associate nursing students had higher positive perception than the other two groups. In addition to that, the Associate Nursing students also had a positive perception to enroll into the profession than the two higher levels of nursing student programs. Specifically, the perception difference was much more in the public image perception and moderately in the practice PPNT subscales. It is reassuring that this study did not find significant differences for values in the student nurses' perceptions of nursing.

In the second hypothesis there was a strong association between the total perception score and to the influencing factors enrolment in the nursing programs for the Associate nursing students than the two higher nursing students groups.

\section{Limitations}

Due to distance study sites and time constraints, the study was quantitative, that couldn't get the internal feeling of the participants. As data was collected through self-administered questionnaires, under reporting and how people respond to questions was challenging.

\section{Abbreviations}

ACHS Asmara College of Health Sciences, ANOVA Analysis of Variance, ANA American Nurse Association, AND Associate Degree Nurse, BSN Bachelors of Science in Nursing. CSPro Census and Survey Processing System, ICU Intensive Care Unit, $\mathrm{MOH}$ Ministry of Health, RN Registered Nurse, PPNT Perception of Professional Nursing Tool, SPSS Statistical Package of Social Science.

\section{Declaration}

I the principal author hereby declare that, I am the sole author of this dissertation entitled "Comparing Perception about Nursing Profession among Degree, Diploma and Associate Nursing Students and Factors Influencing Enrolment in the Nursing Programs". This is my original work and the dissertation or any part thereof has not been submitted for the award of a degree to any other university or 
institution.

\section{Funding}

Funding was given from the National Higher Education and Research Institute (NHERI) and Ministry of Finance Eritrea (MOFE) as an incentive for the fulfillment of the MSc degree. Their role was only on facilitation.

\section{Authors' Contributions}

The principal author $\mathrm{HKG}$ contributed to writing the proposal, collected the raw data, performed a literature search, analysis and wrote the thesis and prepared the manuscript. ZT contributed to mentoring and supervised the whole research. EH contributed to designing the research, data analysis and reporting. All authors read and approved the final manuscript.

\section{Ethical Considerations}

First, the proposal of the study and consent procedure was evaluated by the ACHS research committee, Health Research Proposal Review and Ethical Committee of the Ministry of Health Eritrea has reviewed for research relevance and ethical soundness and was approved on $11^{\text {th }}$ of October 2017. With the ethics clearance paper at hand, permission to conduct the research was obtained from each respective college and before collecting data, purpose of the study was explained to the respondents and written consent was obtained from each participant. The respondents were assured of confidentiality and anonymity by using serial numbers as identifiers and were instructed not to write their names on the questionnaires. The questionnaire was written in English and further explanation and clarification was provided by the data collectors and supervisors as the respondents filled in the questionnaires to avoid any possible misunderstanding and confusion in answering the questionnaires. Finally, respondents were informed that they were free to withdraw their participation if they feel any hesitancy or wish at any stage of the data collection in each questionnaire.

\section{Acknowledgements}

As a principal author, I would like to express my special appreciation and thanks to the data collectors, supervisors and the study participants. In addition to that I would like to say thanks to the authorities of the study sites. Last but not least, special thanks goes to my family for their patience and continuous support throughout my work for this research project.

\section{Competing Interest}

The authors declare that they have no competing interests.

\section{References}

[1] Roberts, K. Virgina, Handerson. A Contemporary nurse 18971996. Accessed on October 19, 2010, from http://www.contemporarynurse.com

[2] American Nurses association, Considering Nursing, Accessed on October 2010 , http://www.nursingworld.org/EspeciallyForYou/StudentNurse s.aspx

[3] Carol Hall, and Dawn R. (2009). What is Nursing? Exploring Theory and Practice. British Library Cataloguing in Publication Data.

[4] Safadi, R. R., Saleh M. Y. M., Nasser O. S. Amre H. M. and Froelicher E. S. (2011, October). Nursing Students Perceptions of nursing a descriptive study of four cohorts. International Nursing Review, 58, p. 420-427. doi: 10.1111/j.1466 7657.2011.00897.

[5] Lliya Wondwossen (2011), Assessment of nurses "erception towards nursing profession in public hospitals under Addis Ababa Health Bureau. Liya. URI: http://localhost:80/xmlui/handle/123456789/8264. Date: 201105-11.

[6] Beck, C. Prestes F., Prochonow A., Silva R., Tavares J., and Nonnemacher C., (2009, Jan/Mar). Professional Identity of Nurses of a County Health Service. Cogitare Enferm, 14 (1), 114-9.

[7] Sand-Jecklin K. E., \& Schaffer, A. J. A. (2006). Nursing students' perceptions of their chosen profession. Nursing Education Perspective, 27 (3), 130-135.

[8] Donelan, K., Destroches C. and Dutwin D.,(2008). The Public perception of nursing careers: The influence of media and nursing shortages. Nursing Economics, 143165.

[9] Prudence Portia Mwini-Nyaledzigbor, Samuel. Atindanbila, Gladstone F. A. and Edward A. (2014). Psychosocial Factors Influencing the Perception and Choice of Nursing as a Profession: A Study at Korle - Bu Nurses' Training College. Psychology and Behavioral Sciences, Vol. 3, No. 1, pp. 25-32. doi: $10.11648 /$ j.pbs. 20140301 .

[10] Lovan, Sherry R., (2009)"Comparing Perceptions of the Nursing Profession Among Associate and Baccalaureate Nursing Students and Registered Nurses". Nursing Faculty Publications. Paper 54. http://digitalcommons.wku.edu/nurs_fac_pub/54 Retrieved Julay 20, 2012

[11] Amal H. E., \& Fatma A., (2017). Nursing Profession as Perceived by Staff Nurses and Its Relation to Their Career Commitment at Different Hospitals. International Journal of Nursing Didactics. doi: http://dx.doi.org/10.15520/ijnd.2017. vol7. iss01.188.13-22.

[12] Mikiyas A. G., Addis A. G. and Bogale E. S. (2015). Assessment of Nurse's Perception Towards Their Profession and Factors Affecting It in Debre Berhan Town Governmental Health Institution, Debre Berhan, Ethiopia. American Journal of Nursing Science, Vol.4,No.6, pp.297-304. doi: 10.11648/j.ajns.20150406.11 
[13] Buerhaus P. I.,Donelan K., Ulrich B. T., Kirby L., Norman L. and Dittus R.(2005). Nursing students perceptions of a career in nursing and impact of a national campaign designed to attract people into the nursing profession. Journal of Professional Nursing, 21 (2), 75-83. doi:org/10.1016/j.

[14] McNeese-Smith, D. K. and Crook M. (2003). Nursing values and a changing nurse workforce. Journal of Nursing Administration, 33, 260-270.

[15] Takase, M., Kershaw E., and Burt L. (2001). Nurseenvironment misfit and nursing practice. Journal of Advanced Nursing, 35, 819-826.

[16] Vahid Z., Leila V., Roghaieh A., Nasim A. and Sedigeh Y. (2014). First and Fourth-Year Student's Perceptions about Importance of Nursing Care Behaviors: Socialization toward Caring. Journal of Caring Sciences, 3 (2), 93-101. doi: 10.5681/jcs.2014.010.
[17] Samah, S., S. Mohamed Roud A. A., Nouf H. H., and Fatimah S. A., (14th -15th May 2017). Nursing Students' Perception Regarding Nursing Program: A descriptive study of four cohorts. Proceedings of Research fora 6th International Conference,. Parice.

[18] Cockrell, Essie Dee Scott, (2002) "Pre-nursing students' perceptions of the nursing profession". LSU Master's Theses. 1626. https://digitalcommons.lsu.edu/gradschool_theses/1626

[19] Momin SKM, H. (2016). Perception and aspiration of final year B. Sc. nursing students towards their professional life. International Journal of Medical Science Public Health: 2508-2511. doi: 10.5455/ijmsph.2016.04032016514.

[20] Takese, M., Maude P., Manias E. (2005). Nurses' job dissatisfaction and turnover intention: Methodological myths and an alternative approach. Nursing and Health Sciences, 7, 209-217. 